\title{
PARTICÍPIOS DUPLOS: NORMA, AVALIAÇÃO E USO ESCRITO
}

\author{
Fernanda Lima Jardim Miara \\ Izete Lehmkuhl Coelho
}

\begin{abstract}
RESUMO
Esta pesquisa investiga as formas de particípio regulares e irregulares, em sentenças ativas e passivas, com base em uma análise dos verbos salvar, pegar, abrir e chegar. A amostra utilizada é formada por um corpus, extraído do jornal Diário Catarinense on-line. Os resultados deste trabalho já apontam que os particípios irregulares, além de mais bem avaliados, são as formas mais frequentes na escrita do PB (MIARA, 2013).
\end{abstract}

PALAVRAS-CHAVE: norma linguística; variação linguística; particípios duplos.

\section{Introdução}

$\tau$ á registros, em nosso país, pelo menos desde o século XIX, de atitudes elitistas de manutenção conservadora do português lusitano. A defesa pela elite brasileira de determinadas normas linguísticas não usadas no Brasil colocava à periferia a maior parte da sociedade, ao valorizar os modos de falar e de escrever de além-mar, em vez dos modos de falar dos brasileiros, em uma época em que, no Brasil, se prezava pela independência e pelo sentimento nacionalista.

Segundo Faraco (2011[2001]), observava-se - e ainda se observa -, no Brasil, a crença em um poderoso imaginário que organiza o mundo social, estabelecendo o que tem ou não valor, inclusive, com respeito à língua. Tal imaginário, como assegura o autor, faz os falantes crerem num ideal de língua 
que supera "qualquer elaboração lógico-racional ou argumentação empírica" (FARACO, 2011[2001], p. 266) que venha a ser apresentada, de maneira que se acredita na existência de formas linguísticas 'certas' e 'erradas'. Essa crença de que há certezas absolutas sobre a língua, refletida em discursos altamente conservadores e puristas, se opóe aos discursos que reconhecem as variedades linguísticas como um sistema natural, ordenado e não caótico (WEINREICH; LABOV; HERZOG, 2006 [1968]).

Há em jogo, pelo menos, dois tipos de forças com respeito ao valor social das formas linguísticas em variação. De um lado, gramáticas e manuais de redaçâo que valorizam, em sua maior parte, a padronização e a uniformização do português - e não seu uso real -, uma vez que elegem como modelo as formas que julgam mais "corretas", discurso que se mantém principalmente nas áreas atreladas à comunicação e ao ensino, de outro lado, discursos acadêmicos que mostram a língua em uso nas mais diversas manifestaçóes da sociedade, da maneira mais coloquial à maneira mais formal, como um sistema complexo, heterogêneo e ordenado.

Tomando esse quadro como ponto de partida, esta pesquisa tem como objetivo apresentar um estudo de caso sobre particípios duplos - regulares e irregulares -, em sentenças ativas e em sentenças passivas, com base em uma análise sincrônica de quatro verbos, a saber, salvar, pegar, abrir e chegar, que se mostram abundantes no particípio, no português do Brasil atual, a fim de apontar o não alinhamento entre regras normativas, avaliação e uso real escrito (MIARA, 2013). Para dar suporte a essas discussóes, trazemos reflexóes a respeito da norma linguística no Brasil, da língua como forma de poder social e do ensino de língua portuguesa. Para tanto, traçamos inicialmente uma breve discussão histórica sobre a construção da norma linguística no Brasil, considerando o fato de que a tentativa de padronização de formas linguísticas tem afetado o ensino de língua portuguesa nas escolas.

Sendo assim, este artigo está organizado da seguinte maneira: caberá à primeira seção tratar da questão histórica a respeito da construção da norma linguística em nosso país; a segunda seção tem como objetivo confrontar algumas gramáticas, bem como o Manual de redação e estilo, consagrado pelo jornal $O$ Estado de S. Paulo, com relação às regras apresentadas por eles quanto à formação de sentenças ativas - com auxiliares ter e haver - e passivas - com auxiliar ser - com particípios duplos, para alguns verbos abundantes no particípio, vi- 
sando assinalar também as dificuldades existentes em se manterem instrumentos normativos que não refletem o uso real escrito; a terceira seção irá trazer alguns resultados empíricos sobre particípios duplos, baseados no estudo de Miara (2013) e em dados retirados do jornal O Estado de S. Paulo, com vistas a reforçar a necessidade de atualização dos instrumentos de ensino (MÓIA, 2004); e, por fim, serão apresentadas as consideraçôes finais, seguidas das referências.

\section{Construção da norma linguística no brasil: reflexões}

Nesta seção, tratamos, especialmente, de tópicos que dizem respeito a questôes sobre a constituição político-cultural da norma, de diferentes normas linguísticas a problemas que estão presentes na cultura nacional, derivados de certo conflito existente entre a padronização da língua e as normas em uso. Todas essas questóes perpassam alguns conceitos como "certo" e "errado", com relação à língua portuguesa e, mais especificamente, ao que se concebe como norma padrão e/ou norma culta da língua.

O conceito de norma, segundo Faraco (2008), se constitui de um conjunto de fatos linguísticos que caracterizam o modo como normalmente falam as pessoas de uma certa comunidade. É possível dizer, então, que uma língua é formada por várias normas: as normas de comunidades rurais, as de comunidades urbanas, as de grupos mais velhos, as que caracterizam a fala dos letrados, as dos analfabetos, aquelas que são usadas pelos jovens das periferias, as que são usadas pelos surfistas, pelos advogados etc. Interessam-nos, neste trabalho, especialmente, as normas que caracterizam o conjunto de fatos linguísticos utilizados pelas pessoas letradas, conhecidas como norma padrão e/ou culta.

É importante ressaltar que as definições de norma ${ }^{1}$ não estão baseadas somente em critérios linguísticos, mas também - e principalmente - em cri-

1 Em sua obra, Faraco (2008) traz quatro concepçóes de norma, a saber, norma padrão, norma gramatical, norma curta e norma culta, sendo que todas elas estão submetidas a modelos usados - ou imaginados - por grupos sociais de maior escolaridade. Entretanto, apenas esta última compreende norma como aquilo que é normal, com a normalidade em uma língua, de maneira que as demais normas se correlacionam com normatividade, o que significa dizer que é norma o que é normativo. Neste trabalho, optamos por estabelecer uma oposição binária entre norma padrão, atrelada à ideia do que é normatizado, prescritivo e imposto, e norma culta, relacionada aos modelos linguísticos usados pelas pessoas escolarizadas nas modalidades faladas e escritas do português do Brasil. 
térios políticos e culturais. Como ressalta Faraco (2008), o padrão ou a norma padrão do português no Brasil se origina essencialmente artificial. De acordo com o autor, foi construído sócio-historicamente para ser referência ou modelo em uma sociedade altamente fragmentada quanto à língua, de maneira a promover a padronização e a uniformização linguísticas, tendo como característica uma codificação abstrata, que acaba por ser distante dos fatos linguísticos reais, já que foi baseada no conceito europeu. Já a definiçẫo de norma culta abrange usos variáveis da língua, utilizados por falantes tradicionalmente urbanos, em situaçóes monitoradas de fala e de escrita, sendo que esses falantes têm acesso à educação superior e à cultura, o que corresponde, em média, a $10 \%$ da populaçâo brasileira atual, ou seja, é uma variedade exclusiva da elite brasileira altamente letrada. Vejamos a seguir um pouco da história de formação da norma culta brasileira.

O século XIX, de acordo com Pagotto (1998), foi o período em que grandes mudanças sintáticas ocorreram e se consolidaram no português do Brasil, fato que pôde ser evidenciado por meio de registros históricos - as constituiçóes de 1824, do Império, e de 1892, da República -, de forma que essas transformaçóes contribuíram para que a própria norma padrão tomasse novas facetas, pois muitas formas da modalidade escrita caíram em desuso, sendo substituídas por outras da oralidade.

A literatura portuguesa, nesse século XIX, promoveu fortemente a divulgação de novas formas linguísticas, além de ter servido como campo de consolidação do discurso da norma culta, uma vez que o Romantismo português permitiu a popularização literária e, consequentemente, a difusão do próprio português. Pagotto (1998) acredita que a mudança de postura em relação à língua falada não se deu de maneira gratuita: estava diretamente associada à ascensão da burguesia. Ora, se antes a literatura estava reservada à nobreza, estaria, naquele momento, voltando-se ao novo mercado consumidor burguês, que viria a consumir formas de expressóes distanciadas das formas clássicas, pois se tratava de outro público leitor, contribuindo para a expansão de formas linguísticas mais populares. De acordo com Pagotto (1998, p. 54), o Romantismo no Brasil, apesar de ter introduzido elementos da fala popular brasileira na escrita da época, não foi valorado como foi em Portugal, pois, enquanto este país deu 
[...] à [sua] língua literária e, portanto, à [sua] norma culta, novas feiçốes, aproximando-a das mudanças em curso no português", no Brasil, ao contrário, parece que "terminamos o século XIX com uma norma culta ${ }^{2}$ ainda mais distante do português brasileiro e extremamente próxima do português europeu moderno (PAGOTTO, 1998, p. 54).

A identidade literária do Brasil, segundo Pagotto (1998), firmou-se baseada na cor local, na paisagem e em personagens, como o índio, mas não foi efetivada por meio da língua, pois esta teria sido neutralizada pelas elites brasileiras, que desejavam manter uma aproximação com a cultura europeia por interesses políticos e econômicos dessas mesmas elites. Também nos mostra o autor que as inovações linguísticas usadas por José de Alencar não foram aceitas pelo discurso elitista, mas justificadas por um estilo brasileiro de escrever, que não pretendia pôr em xeque a identidade linguística forçada entre Brasil e Portugal.

Não adiantou José de Alencar, no seu esforço para abrasileirar a norma escrita, apelar para os clássicos, a fim de mostrar a antiguidade de fatos da língua do Brasil. O que prevaleceu foi a imagem de que somos uma sociedade que fala e escreve mal a língua portuguesa, [...] inferiorizada frente a uma pretensa superioridade lusitana. E tudo o que - no português culto brasileiro - não coincida com a certa norma lusitana passou a ser listado por gramatiqueiros pseudopuristas como erro. (FARACO, 2011[2001], p. 272)

Conforme aponta Faraco (2002), a crítica em relação às transformaçóes da língua portuguesa sempre foi encarada ou como deturpaçóes, numa atitude conservadora purista em moldes lusitanos, ou como inovaçôes possíveis, numa atitude mais flexivel, que buscava reconhecer determinadas inovaçóes, porém limitando-as. Mas, como assinala o autor, foi a cristalização artificial da norma

2 É importante ressaltar que Pagotto (1998), quando discute a construção da norma, no Brasil, não está estabelecendo uma oposição entre norma culta e norma padrão. Neste caso, o termo norma culta utilizado pelo autor se equipara ao conceito de norma padráo definido por Faraco (2008). 
que seguiu a tradição escolar, constituindo a maior parte dos livros didáticos, o que deu à escola o mérito de ensinar a "boa linguagem", uma atitude normativista conservadora que muito se combina com o purismo sempre defendido pelas elites.

Com base no que é perpetuado e prescrito nas gramáticas e em livros didáticos, tudo leva a crer que o ensino pouco mudou nas escolas brasileiras, uma vez que normas diferentes do padrão entram nas discussôes das aulas de língua portuguesa como exemplos do que não deve ser falado ou escrito. Assim também a prescrição unilateral da norma padrão alimenta e sustenta “consultórios gramaticais de imprensa" (FARACO, 2011[2001], p. 273), ultrapassando os muros escolares, como pode ser exemplificado pelo Manual de redação e estilo, publicado por Eduardo Martins, jornalista de $O$ Estado de $S$. Paulo, com sua primeira edição em 1990. Em sua página inicial online, lê-se que o Manual é um "consagrado conjunto de normas da imprensa brasileira" e que "cumpriu essa trajetória exatamente porque sua utilidade não é restrita às redaçôes de jornais e revistas", já que se trata de um guia que orienta a respeito de princípios básicos do nosso idioma, necessários a todos os brasileiros. Além de oferecer um Guia de pronúncia, o Manual também apresenta seções tais como Os cem erros mais comuns, Os dez erros mais graves, Esclareça suas dúvidas (de A a $Z$ ), dentre outras.

Parece que é, principalmente, a imposição de uma norma padrão como modelo ideal e único que tem atuado nas escolas, minimizando a riqueza de nossa língua, com ajuda da mídia, de instrumentos normativos e de gramáticos conservadores. Essa concepçáo de ensino deve, portanto, ser combatida com urgência (MÓIA, 2004), uma vez que ignora, inclusive, o próprio movimento literário de 1922, tão valorizado nas aulas de português. "Atrás disso, há uma longa história, uma história de pelo menos um século e meio na qual a sociedade brasileira construiu de sua língua uma imagem depreciativa" (FARACO, 2011[2001], p. 271), visto que sempre se comparou à "raça lusitana" e se rebaixou à atitude de vassalagem em relação a ela. Sem dúvida, como frisa Faraco (2011[2001], p. 274), "o problema da norma [...] não é simples nem se reduz a questóes apenas linguísticas”, mas está permeado por questóes sociais, de valoração social. Esse quadro é o ponto de partida para as discussóes que seguem. 


\section{As normas e os particípios duplos}

Esta seção tem como objetivo confrontar regras sobre o uso de particípios duplos no português, em sentenças ativas e passivas, expostas em algumas gramáticas pesquisadas por Miara $(2013)^{3}$, bem como regras de formação dessas sentenças apresentadas pelo Manual de redação e estilo, consagrado pelo jornal $O$ Estado de S. Paulo. Essa discussão toma como base que (i) frequentemente os falantes têm dúvidas ao usar as formas do particípio tanto na fala quanto na escrita, e que (ii) a norma que predomina nos instrumentos gramaticais é a padrão, artificial e distante, muitas vezes, do uso real.

Os particípios duplos, entre outros fenômenos linguísticos, representam problemas quanto à normatização da língua (MÓIA, 2004, MIARA, 2013), justamente por gerar opiniōes divergentes, dúvidas e contradições. Observam-se frequentemente generalizaçóes diferentes quanto ao uso real desses verbos pelos falantes e quanto às regras que as gramáticas prescrevem, uma vez que a norma padráo atribui um tipo de regra a esse objeto, ao passo que o sistema gramatical por vezes prevê outro.

Conforme definem Cunha e Cintra (2001, p. 442), verbos abundantes são aqueles "que possuem duas ou mais formas equivalentes, e essa abundância ocorre [...] no PARTICÍPIO, que em certos verbos se apresenta como uma forma reduzida ou anormal [terminada em $-o$ ou em $-e$ ] ao lado da forma regular terminada em -ado ou -ido" [grifo dos autores]. Quanto às regras de uso dos particípios duplos em sentenças ativas e passivas, a maior parte dos autores pesquisados por Miara (2013) - Pereira (1946 [1926]), Rocha Lima (2005 [1972]), Cunha e Cintra (2001) e Azeredo (2008) - seguem a aplicação da regra geral em ativas e em passivas com particípios duplos - ter/ haver + particípio regular e ser + particípio irregular - para a maior parte dos

3 A dissertação de Miara (2013), intitulada "Particípios duplos: usos, desusos e alguns 'intrusos”, por meio de uma abordagem sociolinguística, investigou a variação nas formas de particípio - regular e irregular - de doze verbos, a saber, salvar, imprimir, entregar, pagar, ganhar, gastar, pegar, abrir, escrever, chegar, trazer e descobrir, que compunham sentenças ativas (ter/haver) e passivas (ser), em duas amostras - uma avaliada e uma escrita. Para este estudo, iremos nos concentrar nos resultados trazidos por Miara (2013) para os dados escritos, mais precisamente relacionados aos verbos salvar, pegar, abrir e chegar, além de trazer breves reflexôes sobre a avaliação dos falantes sobre esses mesmos verbos. 
verbos ${ }^{4}$. Alguns autores, como, por exemplo, Barboza (1830), Said Ali (1964 [1931], 1969 [1923], 2008 [1908]) e Bechara (2001 [1999]), assumem que o uso dos particípios varia de verbo para verbo, podendo, em determinados casos, haver variação nessas vozes verbais, assim: ter/haver + particípio regular/irregular e ser + particípio regular/irregular. Resguardadas as diferenças, o Manual de Martins (2014 [1990]) aplica a regra geral de formação dos particípios também sem expandi-la, admitindo somente ter + particípio regular e ser + particípio irregular - para os verbos salvar e pegar, aqui pesquisados 5 .

Em seu estudo sobre o português de Portugal, Móia (2004) mostra que é facilmente observada nas gramáticas do português a falta de consenso no que respeita ao uso de regras do particípio para a formação de sentenças ativas e passivas, a ponto de causar certa agramaticalidade em determinadas construçôes. Por exemplo, em * $O$ novo edifício foi bento pelo padre, constata-se que a aplicação da regra geral - ser + particípio irregular - gera estranhamento a ponto de ser necessário reajustar: foi benzido. Outros casos ainda são exemplificados pelo autor com os verbos absolver e tingir, os quais, semelhantemente, causam estranheza na passiva: ${ }^{*} O$ réu foi absolto $\mathrm{e}^{*}$ As calças foram tintas de azul. Segundo Móia (2004), as formas bento, absolto e tinto, em um momento histórico do português, já foram usadas como particípios, porém para o português atual devem ser compreendidas como adjetivos, como, por exemplo, óleo bento, réu absolto e vinho tinto. Esses casos apenas exemplificam que as formas abundantes do particípio não podem estar sujeitas a um corpus fechado de regras, sem levar em consideração a variação e a mudança linguística.

Problemas de ordem maior são gerados por conta de uma certa necessidade de padronização e de conservação de construçóes com particípios duplos no português, já que "não se comportam todos da mesma maneira [...]. Para cada um dos dois contextos relevantes, há uma gradação na tendência para o uso maior ou menor de um dos particípios. E registram-se mesmo tendências contrárias às generalizaçóes das gramáticas” (MÓIA, 2004, p. 117). Diante

4 Em seu estudo, Miara (2013) toma como constituintes de sentenças ativas os verbos auxiliares ter e haver, como preveem as gramáticas pesquisadas por ela, porém, quanto a sentenças passivas, a autora busca apenas dados com o auxiliar ser, optando, portanto, pela regra geral.

5 A indicação do uso, no Manual, é categórica, com poucas exceçôes: "use ter e haver com os particípios regulares e ser e estar, com os irregulares"; "nos títulos, empregue habitualmente o particípio irregular" (MARTINS, 2014[1990], np). Note que há exceçóes, quando se trata de títulos. 
disso, a preocupação do autor é relevante quanto à necessidade de atualização dos compêndios gramaticais, principalmente aqueles usados nas escolas e nos centros de ensino, em sua maior parte, altamente conservadores.

O ponto aqui não está relacionado a descrever novamente o "certo" ou o "errado", mas a fazer o aluno refletir sobre os diferentes usos, e ter a sensibilidade de compreender que "a história dos particípios varia de verbo para verbo" (SAID ALI, 1964 [1931], p. 147), ainda que determinadas escolhas - conscientes ou não - não sejam igualmente aceitas por todos os falantes do português. Haverá casos em que, segundo Móia (2004, p. 124), uma hierarquização se fará necessária, informando ao aluno que determinada forma "tende a desaparecer", ou até mesmo que corresponde a "uma forma nova cujo uso já se difundiu, ou evidencia forte tendência para se impor", ou talvez que se trate de uma "forma de uso pouco frequente e difícil normalização". Ora, não podemos negar casos complexos, de difícil definição, mesmo porque a avaliação dos falantes sobre determinadas construçôes com particípios nem sempre é a mesma (cf. MIARA, 2013).

Para compreender melhor essas questôes, retomamos aqui uma discussão apresentada por Miara (2013) a respeito do que dizem algumas gramáticas do português sobre normas de construçóes de sentenças ativas e passivas com particípios duplos, confrontando-as às regras encontradas no Manual de redação e estilo, de Martins (2014 [1990]). Escolhemos para este trabalho a análise dos verbos salvar, pegar, abrir e chegar.

O verbo salvar foi escolhido, porque tem uma característica própria quando comparado aos demais verbos: é o único deste grupo que sempre apareceu nas gramáticas pesquisadas por Miara (2013) como verbo abundante no particípio. Porém, é preciso ressaltar que, ainda assim, não há consenso entre os autores quanto ao seu uso em sentenças ativas e passivas. Barboza (1830), Said Ali (2008 [1908], 1969 [1923], 1964 [1931]) e Bechara (2001 [1999]), por exemplo, irão descrever como uso para construçóes com os auxiliares ter/ haver e ser tanto a forma regular como a forma irregular de particípio, sem restrições. Pereira (1946 [1926]) e Rocha Lima (2005 [1972]), em contrapartida, apenas descrevem a variação entre os particípios salvado e salvo nas sentenças ativas, restringindo às passivas a forma irregular. Já Cunha e Cintra (2001), diferentemente, não citam restriçôes para este verbo, o que pode evidenciar que aplicam a regra geral - ter/haver + salvado e ser + salvado/salvo. No Manual 
de redação e estilo, Martins (2014 [1990]) restringe a forma salvado para os auxiliares ter/haver e a forma salvo para o auxiliar ser. Dessa maneira, o que se observa é que, mesmo que os autores pesquisados por Miara (2013) e o Manual concordem que o verbo salvar é portador de dois particípios, não há consenso quanto ao modo de construir sentenças ativas e passivas com relação a esse verbo.

Sobre o verbo pegar, embora seja de larga escala o uso da forma irregular pego - ao menos no Brasil -, dos autores pesquisados por Miara (2013), somente dois o registram como verbo abundante no particípio, a saber, Pereira (1946 [1926]) e Bechara (2001 [1999]). Pereira (1946 [1926], p. 162) amplia a regra geral para a voz ativa, considerando o particípio irregular pego também para os auxiliares ter/haver. Como Bechara (2001 [1999], p. 229) não restringe o uso para a forma pego, em sua lista de verbos abundantes, e considera que a forma pegado tanto pode ser usada em ativa como em passivas, é possível considerar que a forma irregular do verbo pegar seja aceita por ele também em ambas as construçóes. Os demais autores pesquisados por Miara (2013) Barboza (1830), Said Ali (2008 [1908], 1969 [1923], 1964 [1931]), Rocha Lima (2005 [1972]) e Cunha e Cintra (2001) - reconhecem como particípio do verbo pegar somente a forma pegado, o que fica evidente nas palavras de Rocha Lima (2005 [1972], p. 171): “o particípio literário é pegado, com qualquer auxiliar". O Manual também registra o verbo pegar como abundante, porém restringe o uso da forma pegado a ativas e da forma pego a passivas. A escolha por este verbo, nesta pesquisa, se justifica pelo fato de, atualmente, se comportar como um verbo abundante, ainda que a maior parte das gramáticas pesquisadas por Miara (2013) não registrarem a forma pego.

Outro verbo que merece nossa atenção é o verbo abrir. Não há dúvidas de que incluir este verbo na lista de abundantes é, no mínimo, uma questão polêmica. O mais curioso é que, como bem mostrou Miara (2013), o verbo abrir foi registrado por Barboza (1830), já na primeira metade do século XIX, como portador de dois particípios, a saber, um regular - abrido - e outro irregular - aberto. Após quase um século, Pereira (1946 [1926]) ainda registra o verbo abrir como abundante, todavia ressalta que a forma regular abrido, mesmo que correta, estava caindo em desuso naquele momento, sendo o particípio aberto usado comumente em sentenças ativas e passivas. Os demais autores pesquisados por Miara (2013) - Said Ali (2008 [1908], 1969 [1923], 
1964 [1931]), Rocha Lima (2005 [1972]), Cunha e Cintra (2001) e Bechara (2001 [1999]) - tratam o verbo abrir como portador de um único particípio e irregular. O mesmo tratamento é dado por Martins (2014 [1990]), em seu Manual, visto que não faz nenhuma objeção a este verbo.

Interessante é a afirmação de Said Ali (1969 [1923], p. 91) para o verbo desabrir, derivado do verbo abrir. Segundo este autor, "[para o verbo abrir] nunca se usou particípio em -IDO, excetuando desabrir, que faz desabrido em vez de desaberto" [grifos do autor], o que, podemos admitir, se trata de uma afirmação um tanto quanto incoerente. Ora, se descobrir se conjuga como cobrir, por ser derivado deste, porque desabrir não é conjugado como abrir? Obviamente, se levarmos em conta - e levamos - que a terminação nos particípios varia de verbo para verbo, não há problema algum em afirmaçóes como essa, já que é possível assegurar intuitivamente que a frequência de uso de aberto seja maior que abrido, porém é, no mínimo, intrigante não haver sequer reconhecimento de que a forma abrido já foi usada, ainda que se preze por uma escrita padrão ou modelar de uma determinada época.

Além disso, as palavras de Said Ali (1969 [1923]) se mostram contraditórias: se nunca se usou o particípio regular do verbo abrir, como ele mesmo se certifica de que "já em meados do século XV andaria na boca do povo a forma abrido" (SAID ALI, 2008 [1908], p. 154)? A resposta do autor é: "por descuido [o cronista Fernão Lopes] a teria usado, em seus escritos” (SAID ALI, 2008 [1908], p. 154). Ora, não é possível acreditar que se trate de um mero descuido muitos brasileiros ainda usarem esse particípio regular. $\mathrm{O}$ histórico de registro dos particípios do verbo abrir, portanto, é mais um exemplo de que a norma padrão não é a única variedade disponível em uma língua. Mais: com o passar do tempo, as normas que servem como modelo também podem variar, e mesmo mudar, ainda que haja esforço em se eliminar outras possibilidades pertinentes. Mas, sem dúvida, a questão aqui está voltada ao valor e à significação social que cada um dos particípios carrega em si (LABOV, 2008[1972]): parece que abrido recebe avaliaçáo negativa, quando comparada à forma aberto, não havendo restrições linguísticas, nesse caso, mas sociais (cf. MIARA, 2013). Desse modo, enquanto a forma aberto é mais frequentemente usada por falantes que dominam a variedade culta, isto é, por falantes altamente escolarizados, a forma abrido tende a ser usada por pessoas com escolaridade mais baixa. 
Finalmente, o verbo chegar também traz curiosidades e, por conta disso, compóe os verbos analisados neste trabalho. É verdade que nenhuma gramática pesquisada por Miara (2013) assinalou este verbo como abundante, nem mesmo as mais antigas, todavia seu uso abundante parece estar sendo registrado, não apenas na oralidade, mas também na escrita. Ora, o fato de o Manual se preocupar em afirmar que a forma chego "não existe" confirma que se trata de uma forma usual/comum nos dias de hoje, sendo necessário aos discursos mais conservadores colocarem tal inovação em uma seção intitulada Os cem erros mais comuns. Diante disso, muitos se preocupam em reforçar a todo o tempo que o verbo chegar apenas tem como particípio a forma regular chegado - pelo menos para a escrita modelar. Nesse caso, parece se tratar de uma inovação linguística ainda não registrada em instrumentos linguísticos de nossa língua.

O Quadro 1, a seguir, resume as normas de cada autor/gramática/manual para os quatro verbos aqui estudados - salvar, pegar, chegar e abrir:

Quadro 1. resumo de regras para cada autor autor/gramática/manual consultado(a), com relação aos verbos salvar, pegar, abrir e chegar-A se refere a sentenças ativas (ter/haver) e P a passivas (ser).

\begin{tabular}{|c|c|c|c|c|}
\hline Obras & Salvar & Pegar & Abrir & Chegar \\
\hline Barboza (1830) & $\begin{array}{l}\text { A: salvado/salvo } \\
\text { P: salvado/salvo }\end{array}$ & - & $\begin{array}{l}\text { A: abrido/aberto } \\
\text { P: abrido/aberto }\end{array}$ & - \\
\hline $\begin{array}{c}\text { Pereira } \\
(1946[1926])\end{array}$ & $\begin{array}{c}\text { A: salvado/salvo } \\
\text { P: salvo }\end{array}$ & $\begin{array}{c}\text { A: pegado/pego } \\
\text { P: pego }\end{array}$ & $\begin{array}{l}\text { A: abrido/aberto } \\
\text { P: abrido/aberto }\end{array}$ & - \\
\hline $\begin{array}{c}\text { Said Ali } \\
(2008[1908], \\
1969[1923], \\
1964[1931])\end{array}$ & $\begin{array}{l}\text { A: salvado/salvo } \\
\text { P: salvado/salvo }\end{array}$ & - & $\begin{array}{l}\text { A: aberto } \\
\text { P: aberto }\end{array}$ & - \\
\hline $\begin{array}{c}\text { Rocha Lima } \\
(2005 \text { [1972]) }\end{array}$ & $\begin{array}{c}\text { A: salvado/salvo } \\
\text { P: salvo }\end{array}$ & $\begin{array}{l}\text { A: pegado } \\
\text { P: pegado }\end{array}$ & $\begin{array}{l}\text { A: aberto } \\
\text { P: aberto }\end{array}$ & - \\
\hline $\begin{array}{c}\text { Cunha e Cintra } \\
\text { (2001) }\end{array}$ & $\begin{array}{c}\text { A: salvado } \\
\text { P: salvado/salvo }\end{array}$ & - & $\begin{array}{l}\text { A: aberto } \\
\text { P: aberto }\end{array}$ & - \\
\hline $\begin{array}{c}\text { Bechara } \\
(2001 \text { [1999]) }\end{array}$ & $\begin{array}{l}\text { A: salvado/salvo } \\
\text { P: salvado/salvo }\end{array}$ & $\begin{array}{l}\text { A: pegado/pego } \\
\text { P: pegado/pego }\end{array}$ & $\begin{array}{l}\text { A: aberto } \\
\text { P: aberto }\end{array}$ & - \\
\hline $\begin{array}{c}\text { Martins } \\
\text { (2014 [1990]) }\end{array}$ & $\begin{array}{l}\text { A: salvado } \\
\text { P: salvo }\end{array}$ & $\begin{array}{l}\text { A: pegado } \\
\text { P: pego }\end{array}$ & - & $\begin{array}{l}\text { A: chegado } \\
\text { P: chegado }\end{array}$ \\
\hline
\end{tabular}

Fonte: adaptado de Miara (2013, p. 86). 
Conforme de observa no Quadro 1, há diferentes regras para o uso de particípios - regular e irregular - para cada autor/gramática/manual consultado(a). Nota-se que o verbo salvar é reconhecido como abundante em todas as pesquisas, embora com variação na regra apresentada para sentenças ativas e passivas; o verbo pegar é reconhecido como abundante em três delas, e lembrado como não abundante em Rocha Lima (2005 [1972]); já o verbo abrir aparece como abundante apenas nas gramáticas de Barboza (1830) e de Pereira (1946 [1926]); e, por fim, o verbo chegar só se mostra "preocupante" para Martins (2014 [1990]), em seu Manual, sendo reforçado como verbo de particípio único e regular.

Essas considerações nos remetem à seguinte reflexão: se o verbo salvar parece sempre ter se mostrado abundante, se o verbo pegar é abundante para alguns e não para outros autores, se o verbo abrir era abundante e sua forma regular parece ser usada hoje com menor frequência, não havendo mais seu registro nas gramáticas - pelo menos nas obras estudadas por Miara (2013) -, será possível afirmar que o verbo chegar está se tornando abundante? Acredita-se que, embora não se tenham encontrado registros da forma participial chego como particípio (aceitável) do verbo chegar, nas normas que servem como modelo, esse particípio é cada vez mais usado no português do Brasil atual, o que faz do verbo chegar abundante, e, igualmente, dos verbos pegar e abrir.

A próxima seção trará alguns resultados gerais sobre o uso escrito e a avaliação das regras de particípios duplos em sentenças ativas e passivas, para os verbos aqui enfocados - salvar, pegar, abrir e chegar-, a partir do estudo de Miara (2013), somando a análise desta autora também a dados reais de escrita do jornal O Estado de S. Paulo .

\section{Avaliação e uso escrito de particípios duplos: alguns resultados}

A norma padrão, como foi ressaltado, nem sempre é consensual no que respeita ao uso de particípios duplos em construçóes ativas (ter/haver) e passivas $(s e r)$. A depender da gramática ou do autor pesquisado, é possível observar diferentes regras para os mesmos verbos abundantes, o que pode prejudicar, entre outras áreas, o ensino do português (MÓIA, 2004). Por outro lado, as diferentes

6 Os dados retirados do jornal $O$ Estado de S. Paulo, que serão expostos na terceira seção deste artigo, não se trata de uma coleta nos moldes de Miara (2013), mas apenas foram trazidos aqui a título de exemplificação e de reflexão sobre a variação no português do Brasil atual. 
regras apenas reforçam o que é real em nossa língua: o uso das formas de particípio - regular ou irregular - varia de verbo para verbo (SAID ALI, 1964 [1931]), bem como a formação de sentenças - ativas e passivas - com verbos abundantes, e é justamente a variação que pode tornar as aulas de português ainda mais interessantes, uma vez que os alunos podem e devem contribuir com suas opinióes/ avaliações a respeito dos diferentes usos. Contudo, sabe-se que a avaliação nem sempre corresponde ao uso real desses mesmos falantes (LABOV, 2008[1972]), o que significa dizer que muitas pessoas podem dar mais prestígio ao particípio chego, porém usarem com mais frequência a forma chegado e vice-versa.

O levantamento do corpus escrito trazido por Miara (2013), com base no jornal Diário Catarinense online, mostrou um resultado comparável apenas parcialmente com os resultados do teste de avaliação ${ }^{7}$, realizado por esta mesma autora. Neste momento, apresentamos os resultados dos dados escritos, no Gráfico 1 e na Tabela 1, que seguem:

Gráfico 1. percentual referente aos dados escritos coletados por Miara (2013), no jornal Diário Catarinense online, para os particípios dos verbos salvar, pegar, abrir e chegar.

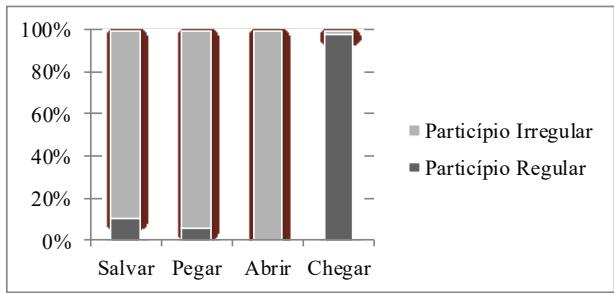

Fonte: adaptado de Miara (2013, p. 183).

7 O teste de avaliação aplicado por Miara (2013) é composto por 46 sentenças - 23 ativas e 23 passivas -, formadas com os verbos salvar, pegar, imprimir, pagar, gastar, ganhar, entregar, chegar, trazer, abrir, escrever e descobrir, em suas formas regulares e irregulares, eleitas pela norma padrão ou não, de acordo com o modelo: (i) $A$ secretária tinhalhavia imprimido $o$ arquivo, (ii) $A$ secretária tinha/havia impresso o arquivo, (iii) $O$ arquivo foi impresso pela secretária e (iv) $O$ arquivo foi imprimido pela secretária. $\mathrm{O}$ teste foi aplicado a 48 catarinenses, distribuídos de acordo com o sexo, a idade e a escolaridade do informante, sendo que cada uma das sentenças poderia ser avaliada como boa, ruim e nem boa nem ruim. A maior parte das avaliaçôes positivas está relacionada às sentenças dos tipos (ii) e (iii), para a maioria dos verbos, uma vez que, de maneira geral, as formas participiais irregulares foram as mais bem avaliadas, totalizando $78,5 \%$ de avaliaçóes boas. Mais esclarecimentos e detalhes sobre a composição e os resultados do teste de avaliação, conferir Miara (2013). 
Tabela 1. quantidade de dados e percentuais para os particípios dos verbos salvar, pegar, abrir e chegar, em relação ao tipo de sentença - ativa e passiva -, referente ao corpus escrito.

\begin{tabular}{|c|c|c|c|c|c|c|}
\hline Verbo & Particípio & Sentença ativa & $\%$ & Sentença passiva & $\%$ & Total \\
\hline Salvar & $\begin{array}{l}\text { Regular } \\
\text { Irregular }\end{array}$ & $\begin{array}{l}2 / 18 \\
2 / 18\end{array}$ & $\begin{array}{l}11 \% \\
11 \%\end{array}$ & $\begin{array}{c}0 / 18 \\
14 / 18\end{array}$ & $\begin{array}{c}0 \% \\
78 \%\end{array}$ & $100 \%$ \\
\hline Pegar & $\begin{array}{l}\text { Regular } \\
\text { Irregular }\end{array}$ & $\begin{array}{l}3 / 51 \\
6 / 51\end{array}$ & $\begin{array}{c}6 \% \\
12 \%\end{array}$ & $\begin{array}{l}0 / 51 \\
42 / 51\end{array}$ & $\begin{array}{c}0 \% \\
82 \%\end{array}$ & $100 \%$ \\
\hline Abrir & $\begin{array}{l}\text { Regular } \\
\text { Irregular }\end{array}$ & $\begin{array}{l}0 / 166 \\
9 / 166\end{array}$ & $\begin{array}{l}0 \% \\
5 \%\end{array}$ & $\begin{array}{c}0 / 166 \\
157 / 166\end{array}$ & $\begin{array}{c}0 \% \\
95 \%\end{array}$ & $100 \%$ \\
\hline Chegar & $\begin{array}{l}\text { Regular } \\
\text { Irregular }\end{array}$ & $\begin{array}{c}68 / 69 \\
1 / 69 \\
\end{array}$ & $\begin{array}{c}98 \% \\
2 \% \\
\end{array}$ & $\begin{array}{l}0 / 69 \\
0 / 69\end{array}$ & $\begin{array}{l}0 \% \\
0 \%\end{array}$ & $100 \%$ \\
\hline & Total & $91 / 304$ & $30 \%$ & $213 / 304$ & $70 \%$ & $100 \%$ \\
\hline
\end{tabular}

Fonte: adaptado de Miara (2013, p. 193).

Como se observa no Gráfico 1, os verbos salvar e pegar apresentaram um percentual bastante elevado para os particípios irregulares salvo e pego, com uso também, ainda que menor, para suas respectivas formas regulares, com registro de $89 \%$ e de $94 \%$, respectivamente. A Tabela 1 expande ainda mais esta análise: das 18 sentenças encontradas para o verbo salvar, quatro são ativas e 14 passivas, sendo que todas as passivas foram construídas com o particípio irregular salvo, o que equivale a 78\% do total, aparecendo a variação somente nas ativas, resultado que concorda com os autores Pereira (1946 [1926]) e Rocha Lima (2005 [1972]). Todavia, na Web, é possível encontrar passivas com o particípio salvado, provando que a variação ocorre nos dois grupos de sentenças - Uma vez instalado o programa, é salvado os lançamentos (tecmundo. com.br, 12/02/2010) -, o que contraria o uso da regra geral para esse verbo, defendida por Cunha e Cintra (2001), Martins (2014 [1990]), além de Pereira (1946 [1926]) e Rocha Lima (2005 [1972]).

Curioso é verificar que o Manual não conseguiu evitar o registro de construçôes ter/haver + salvo no próprio jornal $O$ Estado de S. Paulo, já que há dados desse tipo em seu corpus: Embora a ação adotada no navio pode ter salvo o Melody de ter capturado [...] (estadao.com.br, 26/04/2009); Sigai disse ter guardado a prática na lembrança e acha que isso pode ter salvo sua vida (estadao. com.br, 15/02/2011), dentre outros exemplos semelhantes. 
A Tabela 1 também nos mostra que, das 51 sentenças coletadas para o verbo pegar, nove são ativas e 42 são passivas, sendo que, semelhantemente ao verbo salvar, a variação para o verbo pegar só aparece nas ativas. Percebe-se, portanto, que, embora a frequência de uso do particípio pego seja muito maior, com 94\% dos casos, há ainda casos de construçóes ter/haver + pegado (6\%) nos dados do Diário Catarinense online, constatando a variação. Ainda sobre esse verbo, observa-se que, embora Martins (2014 [1990]), em seu Manual, aplique a regra geral para seu uso, facilmente se encontram construçóes do tipo ter/haver + pego, no jornal O Estado de S. Paulo: A jovem confirmou que não conhecia o motorista e disse ter pego a droga em Cáceres (estadao.com.br, 06/02/2012); Dois pescadores britânicos dizem ter pego o maior tubarão (estadao.com.br, 31/05/2012); dentre outros exemplos. Em resumo, a forma pego não somente aparece como particípio do verbo pegar como é a mais bem avaliada, e a mais usada na escrita, de acordo com os resultados de Miara (2013).

O teste de atitude aplicado por Miara (2013) mostrou que os respectivos particípios irregulares para esses verbos - salvar e pegar - foram os mais bem avaliados. Diante disso, ainda que os autores pesquisados pela autora não cheguem a um consenso quanto ao fato de pegar ser ou não abundante, ele se comporta como tal no português do Brasil, o que evidencia a necessidade de atualização dos instrumentos normativos (MÓIA, 2004).

O verbo abrir, por sua vez, como tem registro na norma padrão atual somente como verbo de um único particípio e irregular, o esperado seria que não aparecesse, no corpus escrito do jornal Diário Catarinense online, a forma abrido, como, de fato, não apareceu, conforme se observa no Gráfico 1, e tampouco teve ocorrência no jornal $O$ Estado de S. Paulo. Porém, esse particípio regular é facilmente encontrado em fontes escritas da Web, e, ainda que com percentual menor, pode receber avaliação positiva (cf. MIARA, 2013), comprovando que esse verbo se mostra abundante atualmente, embora a forma aberto tenha maior frequência de uso. Eis um exemplo, extraído do jornal Diário Catarinense online, em 05/03/2009, nos comentários de leitores: [...] quero parabenizar as autoridades da suiça pq aqui ja tinhao abrido ate uma cpi. Alguns outros exemplos da Web: [...] então quer dizer que nada foi abrido? (twitter.com, 16/11/2013); Agradeço a ATEA por te abrido meus olhos [...] (facebook.com, em 18/07/2012). O que a Tabela 1 nos mostra é que 95\% das 
construções dos dados encontrados por Miara (2013) são construções passivas, sendo $100 \%$ dos casos registrados com o particípio aberto.

O verbo chegar, curiosamente, tem registro de uma única forma escrita com seu particípio irregular chego, em 20/11/12, no jornal Diário Catarinense online: [...] Beatriz Montemezzo, dizia que o acelerador linear já havia chego [...]. É verdade que esse dado corresponde a apenas $2 \%$ da amostra de Miara (2013), como mostra o Gráfico 1, mas sua importância se justifica por, pelo menos, três razôes: foi escrito por um jornalista; é uma forma tão comum que precisa ser lembrada de não existir - conforme foi visto em Martins (2014 [1990]), em seu Manual; o fato de aparecer escrito nos sugere que na fala possivelmente já é usado com frequência. A Tabela 1 revela que todos os dados para os particípios do verbo chegar se trata de sentenças ativas ${ }^{8}$, porém construçôes passivas com o verbo chegar também podem ser encontradas na Web: Pois é chego o dia 19/05 (facebook.com, 19/05/2014); [...] é chego a hora de passar por outras cidades (forums.br.leagueoflegends.com, 12/01/15). Parece que nem mesmo o número de argumentos desse verbo, tampouco sua transitividade, tem impedido a construção de sentenças passivas (cf. MIARA, 2013). De fato, a forma chego está cada vez mais sendo usada na fala espontânea.

Mas, o mais curioso é que, embora a forma chego não tenha sido a mais usada na escrita, parece receber alta avaliaçấo positiva de falantes brasileiros (cf. MIARA, 2013). A forma inovadora para esse verbo, portanto, indica maior prestígio que a antiga. Resultados como esses nos permitem pensar que, pelo fato de as formas irregulares, de maneira geral, serem prestigiosas, os falantes são levados a criar novos particípios, em analogia aos demais, terminados em $-o$, como, por exemplo, pode-se criar chego analogicamente a salvo, pago e gasto (BASÍLIO, 2011 [1987], TEIXEIRA DA SILVA, 2008). Sendo assim, é viável considerar que as formas irregulares são as preferidas da norma culta da língua? Estaria a forma chego indo em direção à fala e à escrita de pessoas mais escolarizadas? Possivelmente.

Fica aqui, pois, evidente que a norma padrão preza por uma uniformização da língua, na qual determinadas possibilidades devem ser evitadas. Todavia, muitas vezes, as construçóes de sentenças ativas e passivas com particípios

8 A construção ser + chegado, conforme mostrou Miara (2013), pode ter outro significado, como, por exemplo, se observa em Ele é chegado a uma fofoca (aulete.uol.com.br, sem data), em que "é chegado" equivale a "gostar". 
duplos mais bem avaliados pelos falantes são exatamente aquelas não eleitas pela norma padrão.

\section{Considerações finais}

A formação da norma linguística do português reflete uma história de exclusão social, que tem sido mantida por instrumentos normativos, os quais, muitas vezes, preservam regras desatualizadas (MÓIA, 2004). Como assegura Faraco (2002), é preciso libertar-se da vassalagem aos portugueses, da "síndrome do erro", eternizada desde o século XIX, uma vez que manter esse tipo de política com a língua somente reforça a afirmação incoerente de que os brasileiros não sabem falar português. O que ocorre é que se perde tempo com regras de construçóes antigas, mas pouco se investe tempo observando a fala e a escrita reais, que representam este século, esta década. E o resultado é que, "tanto para brasileiros, quanto para portugueses, a distância entre o que usam normalmente e o prescrito sempre será grande porque se trata da distância entre o artificial e o natural” (BARBOSA, 2009 [2007], p. 38).

A variação no uso de particípios duplos, em sentenças ativas e passivas, apenas mostra que até hoje as gramáticas e os manuais linguísticos não reconhecem construçóes comumente usadas, tampouco inovações perfeitamente aceitáveis. Ainda que muitos estudos atestem mudanças linguísticas, "mais e mais se constata a distância entre as formas usuais no nosso vernáculo e o português exigido na escrita e prescrito nos manuais de gramática" (PAGGOTO, 1998, p. 50). É verdade que nem todos os particípios são usados com a mesma frequência, já que ficou bastante evidente que as formas irregulares são as mais bem avaliadas, de maneira geral. Porém, não é coerente afirmar que pegar não é abundante, tampouco que as formas abrido e chego não existem ou não são usadas. Ora, não considerar determinados particípios como forma modelar é perfeitamente aceitável em situaçóes de fala e de escrita monitoradas, por uma questão de adequação linguística, mas a variação deve ser tratada nas escolas como normalidade, a fim de que se elimine a concepção de "certo" e "errado".

Como bem assinala Rey (2011[2001], p. 140), nenhuma sociedade pode simplesmente abrir mão da norma padrão, mas o purismo é uma solução preguiçosa, uma vez que "precisa ignorar todo o conhecimento científico da língua para melhor recusar a realidade do uso". Sendo assim, a língua "tem de 
responder às exigências de uma variedade de comunidades, classes, profissóes e grupos de interesse. [...] Qualquer vernáculo é presumivelmente adequado num dado momento para as necessidades de um grupo que o usa" (HAUGEN, 2011[2001], p. 109). E as regras da norma culta são também adequadas para outras necessidades comunicativas desse mesmo grupo.

Nesse aspecto, políticas linguísticas que promovam o fim do preconceito das variedades menos prestigiadas estão diretamente relacionadas à atitude de desconstrução do conceito de que há somente uma forma de se dizer ou de se escrever, e essa atitude deve ser tomada principalmente nas escolas, de modo a promover um discurso não categórico. É papel da escola reconhecer, portanto, que usos não considerados padrão ou culto, como alguns particípios aqui discutidos, são sistemas linguísticos tão estruturados quanto as formas eleitas por essas mesmas normas, sendo necessário abrir mão de atitudes discriminatórias em relação aos falantes de outras variedades.

\section{Referências}

BARBOSA, Afranio Gonçalves. Saberes gramaticais na escola. In: VIEIRA, Silvia Rodrigues e BRANDÁO, Silvia Figueiredo (Orgs.). Ensino de gramática: descrição e uso. Silvia Rodrigues Vieira e Silvia Figueiredo Brandão (Orgs.). 2a reimpressão. São Paulo: Contexto, 2009 [2007], p. 31-54.

BARBOZA, Jeronymo Soares. Grammatica philosophica da lingua portugueza. 2a ed. Lisboa: Typographia da Academia Real das Sciencias, 1830, p. 237-299.

BASÍLIO, Margarida. Teoria Lexical. Série Princípios. Edição online. São Paulo: Ática, 2011 [1987], 79 p.

BECHARA, Evanildo. Moderna gramática portuguesa. 37a ed. rev. e ampl. Rio de Janeiro: Lucerna, 2001 [1999], p. 222-232.

CUNHA, Celso; CINTRA, Luis F. Lindley. Nova gramática do português contemporâneo. Rio de Janeiro: Nova Fronteira, 2001. XXV, p. 441-443.

FARACO, C. A. O Brasil entre a norma culta e a norma curta. In: LAGARES, X; BAGNO, M. Politicas da norma e conflitos linguisticos. São Paulo: Parábola, 2011[2001]. p. 259-275.

A questão da língua: revisitando Alencar, Machado de Assis e cercanias. In: Linguas Instrumentos Linguísticos. Campinas: Pontes, 2002. p. 33-52. 
HAUGEN, Einar. Dialeto, língua, nação. In: Norma linguística. Marcos Bagno (Org.). São Paulo: Loyola, 2011 [2001], p. 97-114.

MARTINS, Eduardo. Manual de redação e estilo. O Estado de S. Paulo digital. http://www.estadao.com.br/manualredacao/esclareca/d.shtm

MÓIA, Telmo. Algumas áreas problemáticas para a normalização linguística - disparidades entre o uso e os instrumentos de normalização. Actas do XX Encontro Nacional da Associação Portuguesa de Linguistica, p. 109-125, Lisboa, APL, 2004. http://www.clul.ul.pt/files/telmo_moia/tmoia_apl2004.pdf

MIARA, Fernanda Lima Jardim. Particípios duplos: usos, desusos e alguns "intrusos”. Dissertação de Mestrado. Universidade Federal de Santa Catarina. Programa de Pós-graduação em Linguística. Florianópolis, SC, 2013. 239 p. https://repositorio.ufsc.br/bitstream/handle/123456789/107342/319589. pdf?sequence $=1$

PAGOTTO, E. G. Norma e condescendência: ciência e pureza. Linguas Instrumentos Linguísticos. Campinas: Pontes, 1999. p. 49-68.

ROCHA LIMA, Carlos Henrique da. Gramática normativa da língua portuguesa. 44a ed. Rio de Janeiro: José Olympio, 2005 [1972]. p. 168-171.

REY, Alain. Usos, julgamentos e prescrições linguísticas. BAGNO, Marco (Org.). Norma linguistica. Sáo Paulo: Loyola, 2011 [2001]. p.115-144.

SAID ALI, M. Gramática Histórica da Língua Portuguesa. 3a. ed. São Paulo: Melhoramentos, 1964 [1931]. p. 146-154.

- Gramática secundária da língua portuguesa. $8^{\mathrm{a}}$ ed. São Paulo: Melhoramentos, 1969 [1923]. p. 91-96.

. Dificuldades da lingua portuguesa. $7^{\mathrm{a}}$ ed. Rio de Janeiro: ABL: Biblioteca Nacional, 2008 [1908]. p. 149-162.

TEIXEIRA DA SILVA, Inaciane. $O$ uso do particípio em formaçóes verbais no português do sul do Brasil. Dissertação de Mestrado. Pós-graduação em Letras da Universidade Federal do Rio Grande do Sul. Porto Alegre, 2008. 95p. http://www.lume.ufrgs.br/bitstream/handle/10183/17213/000708232.pdf

WEINREICH, Uriel; LABOV, Willian; HERZOG, Marvin I. Fundamentos empíricos para uma teoria da mudança linguistica. Trad. Marcos Bagno. São Paulo: Parábola, 2006 [1968]. p. 87-126. 


\title{
DOUBLE PARTICIPLES: STANDARD LANGUAGE, EVALUATION AND WRITTEN DATA
}

\begin{abstract}
This research aims to investigate the variation in the regular and irregular past participle forms, in active sentences and in passive sentences, based on a synchronic analysis of four verbs: salvar (to save), pegar (to take), abrir (to open) and chegar (to arrive). The sample is formed by a corpus, extracted from the online newspaper Diário Catarinense online. The results of this work show that irregular participles are best evaluated forms and they are the most frequent forms in written data in PB (cf. MIARA, 2013).
\end{abstract}

KEYWORDS: standard language; linguistic variation; double participles.

Recebido em: 31/03/2015

Aprovado em: 12/09/2015 